DOI: 10.12957/demetra.2016.16789

\title{
Pensadores da alimentação: trabalhadores debatem suas dificuldades para incorporar práticas alimentares saudáveis
}

\author{
Thinkers of feeding: workers discuss their difficulties to incorporate healthy eating habits
}

\author{
Mariana Maia Melo \\ Michelle Cristine Medeiros da Silva ${ }^{2}$ \\ Karine Cavalcanti Mauricio de Sena \\ Evangelista $^{3}$ \\ Fernanda Rafaella de Melo Silva ${ }^{4}$ \\ 'Universidade Federal do Rio Grande do Norte, \\ Departamento de Nutrição, Curso de Nutrição. \\ Natal-RN, Brasil \\ ${ }^{2}$ Universidade Federal de Campina Grande, \\ Departamento de Ciências Sociais. Natal-RN, \\ Brasil. \\ ${ }^{3}$ Universidade Federal do Rio Grande do Norte, \\ Departamento de Nutrição, Curso de Ciências dos \\ Alimentos. Natal-RN, Brasil. \\ ${ }^{4}$ Universidade Federal do Rio Grande do Norte, \\ Departamento de Nutrição, Curso de Cuidados \\ Paliativos. Natal-RN, Brasil. \\ Correspondência / Corrrespondence \\ Mariana Maia Melo \\ E-mail: mariana.nutrica004@gmail.com
}

\section{Resumo}

As doenças crônicas não transmissíveis têm sido a causa de mais da metade dos óbitos no mundo, tendo, dentre várias outras doenças associadas, a obesidade. Um dos fatores para o aumento da obesidade são as práticas alimentares não saudáveis, e o objetivo deste trabalho foi realizar um diagnóstico educativo das dificuldades encontradas pelos funcionários do Hospital de Pediatria da Universidade Federal do Rio Grande do Norte para incorporar práticas alimentares saudáveis no seu cotidiano. A alimentação envolve aspectos culturais, sociais, afetivos e sensoriais, fazendo com que as pessoas não se alimentem somente buscando nutrientes, mas também os significados dos alimentos escolhidos. Assim, uma intervenção de educação alimentar e nutricional deve incluir esses aspectos e também ser precedida por diagnóstico educativo, para cercar a questão da subjetividade humana intrínseca ao comer. Para traçar este diagnóstico educativo, foram dirigidas sessões de grupos focais, com os 14 sujeitos da pesquisa, visando obter os dados com base numa discussão focada em um tema específico. Como resultados podemse elencar cinco categorias de dificuldades: "não há tempo", "práticas alimentares arraigadas", "falta de acesso a modos de vida saudáveis", "o saboroso não é saudável” e "a dieta é sacrifício". Portanto, as estratégias de educação alimentar nutricional devem ocorrer focadas no autocuidado, tendo a alimentação adequada como expressão de cidadania. Além disso, sugere-se que práticas de alimentação saudável sejam incentivadas e fomentadas no ambiente de trabalho.

Palavras-chave: Obesidade; Práticas Alimentares; Educação Alimentar e Nutricional; Promoção da Alimentação Saudável. 


\section{Abstract}

Chronic non-communicable diseases have been the cause of more than half of deaths in the world, and, among many other diseases, obesity. One of the factors for the increase in obesity is unhealthy eating habits, and this study aimed to present an educational diagnosis of the difficulties found by workers at Pediatric Hospital of Federal University of Rio Grande do Norte to incorporate healthy eating habits in their daily lives. Feeding involves cultural, social, emotional and sensory aspects, making people feed seeking not only nutrients but also the significance of the chosen food. Thus, a food and nutrition education intervention should include these aspects and be preceded by educational diagnosis, to surround the question of intrinsic human subjectivity to eat. To trace this educational diagnosis, focus group sessions were addressed, with 14 research subjects, to obtain data on the basis of discussion focused on a specific theme. The results can be to list five categories of problems: "no time", "entrenched eating habits," "lack of access to healthy lifestyles", "tasty is unhealthy" and "diet is sacrifice." Therefore, nutritional food education strategies must take place focused on self-care, and adequate food as an expression of citizenship. Furthermore, it is suggested that healthy eating practices are encouraged and promoted in the workplace.

Key words: Obesity; Eating Habits; Food and Nutritional Education; Promoting Healthy Eating.

\section{Introdução}

A alimentação envolve diferentes aspectos que manifestam valores culturais, sociais, afetivos e sensoriais. Assim, as pessoas não se alimentam de nutrientes, mas de alimentos e preparações escolhidas e combinadas de uma maneira particular, com cheiro, cor, temperatura, textura e sabor; alimentam-se também de seus significados e dos aspectos simbólicos. E, neste contexto, cada vez mais importância é dada às ideias que os sujeitos têm sobre suas práticas alimentares, sobre sua opinião a respeito das orientações dadas pelos serviços de saúde, sobre as dificuldades para implementar mudanças na alimentação e, principalmente, sobre seus valores e condição emocional em que se encontram. ${ }^{1}$

Em suma, os programas educativos precisam ser sempre precedidos de diagnósticos educativos, que são diferentes dos diagnósticos da situação de saúde. Os indicadores vitais, antropométricos 
e relativos aos índices de morbidade não nos dizem muito sobre a subjetividade das pessoas. Para intervir no campo da educação alimentar e nutricional, é preciso mais: é preciso conhecer as razões pelas quais o comportamento alimentar ocorre dessa forma. $\mathrm{O}$ acesso ao pensamento dos sujeitos e a compreensão que se obtém a partir disso permitem formular intervenções e programas mais adequados às realidades e mais significativos aos sujeitos, portadores de uma história, que não pode ser ignorada nas ações propostas, seja no campo da alimentação ou em qualquer outro campo da saúde. ${ }^{2}$

Do total de óbitos ocorridos no mundo em 2008, 63\% foram relacionados às doenças crônicas não transmissíveis (DCNT). No Brasil as DCNT são também a principal causa de mortalidade, sendo 80,7\% dos óbitos por doenças crônicas, em 2009. ${ }^{3}$ A obesidade é considerada uma doença integrante do grupo de DCNT. ${ }^{4}$ Ao mesmo tempo que declina a ocorrência de desnutrição em crianças e adultos num ritmo acelerado, aumenta a prevalência de sobrepeso e obesidade na população brasileira. A projeção dos resultados de estudos efetuados nas últimas três décadas é indicativa de um comportamento claramente epidêmico do problema. Estabelece-se, dessa forma, um antagonismo de tendências temporais entre desnutrição e obesidade, definindo uma das características marcantes do processo de transição nutricional do país. ${ }^{5}$

A prevalência da obesidade está em ascensão e um dos fatores que contribuem para isso é a transição nutricional, com o aumento do fornecimento de energia pela dieta e redução da atividade física, o que alguns autores denominam de "estilo de vida ocidental contemporâneo". A intervenção nutricional é necessária, pois se sabe que a obesidade causa diversos danos à saúde, além de favorecer o aparecimento de doenças associadas, como dislipidemias e diabetes. ${ }^{6}$

A intervenção educativa competente, portanto, deve pautar-se a partir dessas informações sobre o adoecimento das populações, mas também, substancialmente, pelo significado que os sujeitos atribuem a suas práticas alimentares. Tais informações são diferentes, contemplam apreensão de significados, de percepções, de experiências de vida, de crenças e atitudes, porém complementares, daquelas obtidas por meio dos estudos epidemiológicos que identificaram os problemas alimentares. ${ }^{2}$ Frequentemente, veem-se estudos sobre antropometria ou consumo alimentar que concluem pela necessidade de intervenção educativa para resolver o problema encontrado.-9

Ações de promoção da saúde impõem a criação de espaços democráticos e participativos, a fim de estabelecer uma aproximação com a realidade dos indivíduos e das populações. Nesse aspecto, a educação nutricional assume papel fundamental para o exercício e fortalecimento da cidadania alimentar. A prática do nutricionista assume o desafio de promover uma educação nutricional eficaz, com ações que promovam mudanças nos hábitos alimentares dos indivíduos e de suas famílias. ${ }^{10}$

Esse desafio foi percebido, por exemplo, nas vivências do pesquisador no projeto de extensão Mais Saúde, que tem como objetivo a promoção da qualidade de vida dos funcionários do Hospital de Pediatria da UFRN. Durante a realização das atividades do projeto, foi detectada a necessidade 
de uma intervenção mais profunda para compreender as práticas alimentares, pois apesar de esses funcionários receberem orientação nutricional e relatarem conhecer os princípios da alimentação saudável, afirmavam não conseguir implementar tais práticas em suas vidas. Este estudo surge como uma tentativa de compreender essa questão, considerando que a compreensão é o primeiro passo para o diálogo em uma Educação Alimentar e Nutricional efetiva. Assim, o objetivo deste trabalho é realizar um diagnóstico educativo das dificuldades encontradas pelos funcionários para incorporar práticas alimentares saudáveis no seu cotidiano.

\section{METODOLOGIA}

Trata-se de estudo transversal de caráter qualitativo. Os sujeitos da pesquisa foram participantes do projeto de extensão multidisciplinar Mais Saúde que voluntariamente concordaram em participar da pesquisa. O projeto foi uma estratégia elaborada pelo setor de recursos humanos do Hospital de Pediatria da UFRN, visando fomentar o bem-estar no ambiente de trabalho. O objetivo geral do Mais Saúde era desenvolver um projeto de qualidade de vida no trabalho que propiciasse a motivação dos trabalhadores, tornando o trabalho mais agradável e amenizando as dificuldades oriundas deste, especialmente em se tratando de um hospital pediátrico, em que o cuidador necessita ser constantemente cuidado para oferecer um serviço mais humanizado. No campo da Nutrição, o pesquisador e bolsista do projeto eram responsáveis por realizar orientação nutricional nos setores de enfermaria, farmácia, nutrição, psicologia, ambulatório, secretaria acadêmica e recursos humanos, durante o horário de trabalho.

Na época, participavam do projeto cerca de 40 funcionários. Com o desejo de a princípio trabalhar com a amostra integral, todos foram informados sobre a pesquisa e convidados a participar do estudo. Apenas 16 concordaram voluntariamente em participar, alegando a jornada de trabalho e a dificuldade em despender mais tempo no ambiente de trabalho para participar das sessões de grupo focal. Sendo assim, o critério de seleção da amostra foi a não probabilística por conveniência. A pesquisa qualitativa não prioriza a quantidade da amostra, mas a qualidade do tratamento dos dados. Ainda assim, durante o trabalho com os grupos focais, pode-se observar a saturação dos dados, momento em que as entrevistas já não acrescentavam mais novidade e seu conteúdo se torna repetitivo. Segundo Bauer e Gaskell, este é o momento de parar a fase de coleta, encerrar as entrevistas. ${ }^{11}$ Este critério de finalização foi observado durante o manejo com grupos focais.

Os critérios de inclusão para a pesquisa foram: ser público-alvo do projeto de extensão Mais Saúde destinado aos funcionários regulares do HOSPED durante a realização da pesquisa, e ter disponibilidade de tempo na rotina de trabalho para as atividades propostas em grupo. E os critérios de exclusão foram: estar em período de férias e/ou licença durante as fases de coleta de dados. 


\section{Questões éticas}

Esta investigação observou as diretrizes e normas regulamentadoras de pesquisas envolvendo seres humanos, segundo a Resolução n. 466/12, do Conselho Nacional de Saúde. A pesquisa foi aprovada pelo Comitê de Ética em Pesquisa do Hospital Universitário Onofre Lopes (HUOL/ UFRN), segundo CAAE 30213413.3.0000.5292. Todos receberam uma cópia do Termo de Consentimento Livre e Esclarecido, com a finalidade de cumprir as exigências do Comitê de Ética da UFRN, para pesquisas sobre pessoas, e assegurar aos participantes o sigilo da coleta de dados. No momento da assinatura, foram esclarecidos os objetivos do estudo e como se daria o andamento da pesquisa. Como contrapartida à sua colaboração com a pesquisa, os sujeitos receberam orientações frequentes sobre suas práticas alimentares.

A fim de manter o sigilo da identidade de cada um, foram escolhidos como pseudônimos para os participantes nomes de filósofos famosos, visto que o estudo busca gerar um pensamento reflexivo sobre alimentação. Os pseudônimos escolhidos, por termos tratado tais sujeitos como pensadores de sua própria alimentação, foram o de filósofos e filósofas: Hannah, Simone, Maria, Edith, Susanne, Sarah, Catarina, Elizabeth, Marilena, Rosa, Heloísa, Louise, Félix e Tales. O pesquisador comprometeu-se em retornar os resultados da pesquisa aos participantes, após a apresentação.

\section{Diagnóstico nutricional simplificado}

Para a caracterização do grupo, realizou-se avaliação antropométrica simplificada dos funcionários do HOSPED/UFRN (Hospital de Pediatria), a fim de obter as primeiras informações necessárias para o diagnóstico nutricional dos participantes.

Por avaliação antropométrica simplificada compreende-se: o pesquisador aferiu peso e altura dos voluntários durante o horário de trabalho, para a realização do cálculo do IMC (índice de massa corpórea). A aferição das medidas antropométricas foi realizada de acordo com o Manual de Capacitação para Procedimentos Antropométricos ${ }^{12}$ com algumas adaptações para o equipamento da UAN (Unidade de Alimentação e Nutrição) do local, que estava disponível para a atividade. Os valores foram demonstrados de acordo com as classificações estabelecidas pela Organização Mundial da Saúde (1995) para adultos, segundo a tabela 1. A análise dos dados foi por frequência simples e apresentada em formato de tabela e gráfico.

\section{Diagnóstico educativo}

O diagnóstico educativo é um olhar antecipado a respeito das impressões e dificuldades que o indivíduo ou grupo vivencia diante da realidade investigada. Este tipo de atividade fundamenta as ações de educação alimentar e nutricional, pois permite entender e alcançar com mais facilidade o sentimento e o significado das atitudes do outro. 
Conforme Boog explica, um diagnóstico prévio do consumo alimentar e de como se vem lidando com os problemas alimentares ajuda o profissional da saúde a pensar em conteúdos que possam ser significativos, porque responderão a problemas reais vividos e sobretudo sentidos pelas pessoas, no cotidiano. ${ }^{2}$ Complementa afirmando que toda ação educativa deve ser precedida de um diagnóstico educativo. É desejável que o conhecimento seja o mais amplo possível e, a priori, nenhuma informação é desnecessária. ${ }^{2}$

O grupo focal tradicional compreende seis a oito pessoas desconhecidas anteriormente, que se encontram em um ambiente confortável por um tempo entre uma a duas horas. Os participantes e o moderador se sentam num círculo, de modo que possa haver um contato frente a frente entre cada um. Quando as pessoas se sentam, a primeira tarefa do moderador é apresentar a si próprio, o assunto e a ideia de uma discussão grupal. ${ }^{11}$

Durante a pesquisa, duas pessoas precisaram se ausentar, uma por causa de uma nova proposta de emprego e outra pela rotina específica de trabalho no hospital, que não permitia a pontualidade nos grupos focais. Sendo assim, ambas saíram por livre e espontânea vontade. Finalizou-se, assim, com 14 voluntários até o final da pesquisa, divididos em dois grupos de sete pessoas.

Para começar este processo, o moderador pediu a cada participante que se apresentasse dizendo o nome, e acrescentou que aqueles que desejassem adicionassem alguma informação pessoal que pudesse levar o grupo a conhecê-lo um pouco mais. Cada contribuição terminou com o moderador dizendo "obrigado", usando o primeiro nome da pessoa. Como na pesquisa em profundidade, o moderador tinha um tópico-guia que sintetizava as questões e assuntos da discussão. O moderador encorajava ativamente todos os participantes a falar e responder aos comentários e observações dos outros membros do grupo ${ }^{11}$

Segundo Boog, onde quer que aconteça a ação educativa, é relevante conhecer o "outro". ${ }^{2}$ Por isso, após a aferição das medidas antropométricas, os participantes foram convidados a responder a um questionário objetivo sobre hábitos alimentares, que foi adaptado pelo entrevistador de um modelo existente no Portal da Saúde, ${ }^{13}$ com o título "Como está sua alimentação?”. A esse instrumento foi acrescentada uma questão referente ao tabagismo, e foram adaptadas algumas perguntas do questionário original, para facilitar a quantificação de porções ingeridas dos alimentos. As respostas obtidas nos questionários serviram como subsídio para o roteiro de perguntas utilizado no primeiro momento do grupo focal, a fim de levantar a discussão sobre os fatores que influenciam o padrão alimentar de cada um.

\section{Conhecendo o grupo no âmbito da pesquisa}

Na primeira sessão, os participantes foram avisados de que o grupo em que estavam inseridos nesse dia seria o mesmo para o segundo momento, para evitar que a mudança de grupo causasse 
constrangimento ou timidez e, assim, se perdesse a essência do grupo focal. Após as boas-vindas, todos foram estimulados a pensar um pouco sobre o significado da alimentação no seu dia a dia, sem que o moderador mencionasse a palavra "saudável”, para não ser tendencioso.

Para que os participantes se apresentassem, foi realizada uma dinâmica de motivação, em que era sugerido um roteiro de respostas: "Meu nome é...", "trabalho no setor...", "se eu pudesse ser um alimento, eu seria...", "porque...". Depois das apresentações, foi realizada uma atividade para conhecer as representações que os participantes faziam para determinados alimentos. A mediação para este momento foi pensada previamente a partir dos dados coletados pelos questionários, aplicados em um momento prévio (avaliação antropométrica simplificada). As respostas apontaram a necessidade de dialogar sobre quatro categorias de alimentos.

Para cada categoria foi preparada, em Power Point, uma sequência de imagens desses alimentos prontos para o consumo. Os participantes foram convidados para o exercício da Técnica de Associação Livre de Palavras (TALP) que, de acordo com Nóbrega \& Coutinho, ${ }^{14}$ tem o intuito de que espontaneamente surjam associações livres e rápidas de palavras relativas ao assunto explorado, a partir de uma frase indutora, como a que utilizei: "Cite 2 a 3 adjetivos sobre esses alimentos". Eles escreviam as palavras num papel e devolviam ao moderador do grupo. Esse momento se repetiu para as quatro categorias de alimentos.

Em seguida, o moderador retomava lendo rapidamente todas as palavras que surgiram, pedindo que ficassem à vontade para comentar o que escreveram. Algumas perguntas foram formuladas anteriormente, mas na maior parte do tempo, eles ficaram livres para comentar e discutir sobre suas próprias dificuldades em aderir à alimentação saudável. Depois foi levantada uma discussão para a busca de alternativas que driblassem essas dificuldades, deixando a conversa fluir livremente. Para finalizar, foi sugerido que eles escrevessem uma promessa para um 2013 mais saudável e gostoso." Esse material permaneceu com eles.

\section{Diálogo dirigido}

Na segunda sessão, foi exibido um vídeo editado com recortes do documentário Muito além do peso, que trata a obesidade infantil como a maior epidemia infantil da história, e traz como uma das causas a alimentação industrializada. Os pontos-chave discutidos no primeiro momento dos grupos focais determinaram a escolha dos recortes para o vídeo utilizado na pesquisa. O vídeo em questão foi selecionado com o intuito de estimular as boas práticas alimentares, além de servir como estratégia de contribuição para o segundo roteiro de discussão em grupo, que consistiu na proposta de formação de um ranking pessoal, em que cada um responderia: "colocando numa

* A coleta de dados da segunda sessão com os grupos focais foi realizada nos dias 14 e 21 de agosto de 2013 ; portanto, a promessa foi uma meta pensada para ser cumprida até o final desse ano. 
ordem de maior para menor dificuldade, como vocês organizariam os aspectos que dificultam os seus hábitos alimentares saudáveis?”. Novamente, eles elencaram algumas alternativas para driblarem as dificuldades citadas.

O encerramento se deu com a degustação de uma salada de frutas e entrega de lembrancinhas. Os dois grupos focais passaram pela mesma sequência de etapas e tiveram seus momentos gravados e transcritos. Foram dois momentos para cada grupo, totalizando quatro encontros. As sessões duravam em média 90 minutos e ocorriam semanalmente de forma alternada entre os grupos, sendo numa semana a vivência do primeiro momento para o grupo 1, e em outra semana o mesmo com o grupo 2 , e assim por diante.

As respostas obtidas dos questionários e justificativas que determinaram a decisão das categorias de alimentos e as palavras da TALP foram organizadas em um quadro síntesepara melhor visualização dos resultados, como sugere Bardin. ${ }^{15}$ Os grupos focais foram analisados, igualmente, segundo a definição para a análise de conteúdo:

Um conjunto de técnicas de análise de comunicação visando a obter, por procedimentos sistemáticos e objetivos

de descrição do conteúdo das mensagens, indicadores (quantitativos ou não) que permitam a inferência de conhecimentos relativos às condições de produção/recepção destas mensagens. ${ }^{15}$

Essa análise foi feita em três fases, sendo a primeira a Pré-análise, em que ocorreu a realização do primeiro contato com o material por meio de uma leitura rápida; em seguida, a Exploração do material foi realizada de acordo com a escolha das unidades de análise, enumeração e categorização dos dados; por fim o, Tratamento dos dados, inferência e interpretação consiste na fase em que houve a produção de gráficos, quadros, diagramas ou figuras, a fim de dar significância aos dados e destaque das informações obtidas. ${ }^{15}$

\section{RESULTADOS}

\section{Diagnóstico nutricional simplificado}

A amostra foi de 14 voluntários, dentre eles 12 mulheres e dois homens, com faixa etária variando de 20 a 46 anos de idade, atuando nos seguintes setores do hospital: farmácia, ambulatório, psicologia, nutrição, recursos humanos e secretarias do departamento de pediatria e acadêmica. Quanto a classificação do IMC, 14\% (2 pessoas) estavam em obesidade, 29\% em sobrepeso (4 pessoas) e $57 \%$ em eutrofia (8 pessoas).

Segue-se a tabela 1 com os dados para realização do diagnóstico nutricional simplificado dos voluntários, e a respectiva classificação do IMC, segundo a OMS (1995). 
Tabela 1. Dados coletados para o diagnóstico nutricional simplificado dos voluntários e classificação do IMC, segundo a OMS (1995).

\begin{tabular}{|c|c|c|c|c|c|c|}
\hline Sexo $^{1}$ & Idade $^{1}$ & $\begin{array}{l}\text { Setor de } \\
\text { atuação }^{1}\end{array}$ & $\begin{array}{l}\text { Peso } \\
(\mathrm{Kg})^{1}\end{array}$ & $\begin{array}{c}\text { Altura } \\
(\mathbf{c m})^{1}\end{array}$ & $\begin{array}{c}\text { IMC } \\
\left(\mathbf{K g} / \mathbf{m}^{2}\right)\end{array}$ & $\begin{array}{c}\text { Classificação } \\
\text { do } \text { IMC }^{2}\end{array}$ \\
\hline Feminino & 32 & $\begin{array}{l}\text { Recursos } \\
\text { Humanos }\end{array}$ & 56,3 & 161,0 & 21,7 & Eutrofia \\
\hline Feminino & 28 & Ambulatório & 65,4 & 150,5 & 28,8 & Sobrepeso \\
\hline Feminino & 23 & Farmácia & 55,1 & 165,0 & 20,2 & Eutrofia \\
\hline Feminino & 23 & Farmácia & 65,7 & 165,0 & 24,1 & Eutrofia \\
\hline Feminino & 24 & Psicologia & 70,4 & 155,0 & 29,3 & Sobrepeso \\
\hline Feminino & 42 & Nutrição & 52,7 & 145,0 & 25,0 & Sobrepeso \\
\hline Masculino & 46 & $\begin{array}{l}\text { Secretaria do } \\
\text { Departamento } \\
\text { de Pediatria }\end{array}$ & 82,4 & 162,0 & 31,3 & Obesidade \\
\hline Feminino & 27 & $\begin{array}{c}\text { Direção } \\
\text { acadêmica }\end{array}$ & 93,6 & 165,5 & 34,1 & Obesidade \\
\hline Feminino & 41 & Ambulatório & 65,5 & 161,5 & 25,1 & Sobrepeso \\
\hline Feminino & 38 & Farmácia & 56,1 & 151,0 & 24,6 & Eutrofia \\
\hline Feminino & 20 & Farmácia & 60,9 & 159,0 & 24,0 & Eutrofia \\
\hline Feminino & 32 & Psicologia & 45,3 & 159,0 & 17,9 & Eutrofia \\
\hline Feminino & 26 & Psicologia & 54,7 & 159,5 & 21,5 & Eutrofia \\
\hline Masculino & 37 & $\begin{array}{l}\text { Secretaria do } \\
\text { Departamento } \\
\text { de Pediatria }\end{array}$ & 64,7 & 164,5 & 23,9 & Eutrofia \\
\hline
\end{tabular}

Fonte: 1- Coleta de dados do TCC, nos dias 17 e 18 de julho de 2013, no refeitório do hospital. 2- OMS, 1995.

Os resultados também foram representados a seguir, no gráficol, para melhor visualização quanto ao diagnóstico nutricional simplificado. 


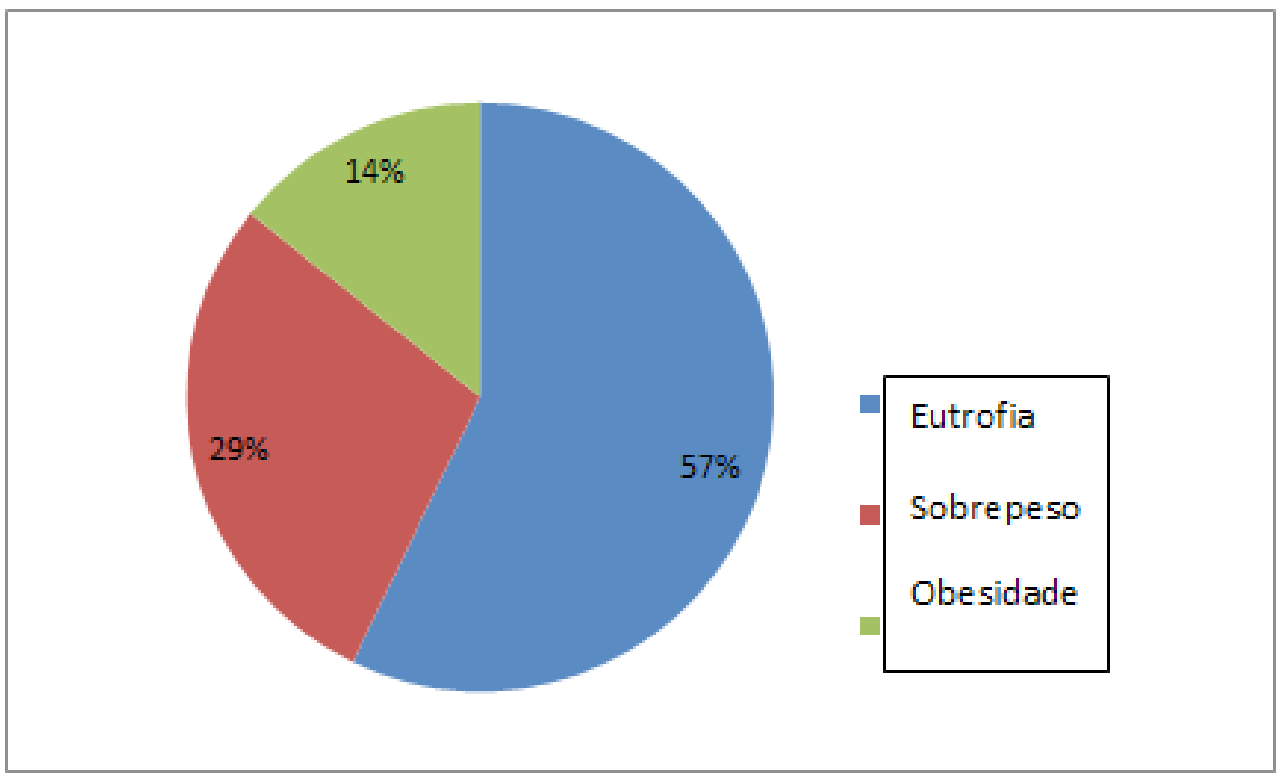

Gráfico 1. Classificação do IMC, segundo a OMS (1995)

Fonte: Coleta de dados do TCC, nos dias 17 e 18 de julho de 2013, no refeitório do hospital

\section{Diagnóstico educativo}

Diante das respostas obtidas nos questionários, foi possível perceber a necessidade de abordar com ênfase os temas de algumas perguntas, os quais foram classificados em quatro categorias: frutas, embutidos, doces e água. Partindo dos princípios e orientações do Guia Alimentar para População Brasileira, ${ }^{16}$ as categorias frutas e água foram escolhidas devido a sua importância na alimentação saudável diária; além disso, foi observado que o consumo de ambas era reduzido. Já as categorias embutidos e doces, representam alimentos que devem ser evitados ou consumidos em pequena quantidade; no entanto, foi observado o consumo frequente desses alimentos no dia a dia de muitos.

A primeira sessão com os dois grupos focais, gerou uma série de palavras associadas a cada categoria, de acordo com a TALP. A quantidade das palavras em cada categoria não é uniforme, visto que era facultada aos sujeitos a inserção de duas ou três palavras, conforme sugestão da questão indutora. 


\section{DISCUSSÃO}

\section{Dialogando sobre as dificuldades}

\section{Não há tempo}

O tempo, ou na verdade a falta dele, é o vilão na história quando se fala em dificuldades para realizar uma alimentação saudável. Todos os participantes nos dois grupos focais citaram esse aspecto como limitação primordial diante da rotina de trabalho ou estudo de cada um.

Nos dias de hoje, é comum a queixa de falta de tempo e muitas pessoas alegam que é por este motivo que não fazem refeições regulares, que comem sempre muito rapidamente e que, não raro, fazem outras coisas enquanto comem. Muitas pessoas têm que percorrer trajetos muito longos entre suas casas e os locais de trabalho ou estudo e o trânsito caótico em muitas cidades subtrai mais desse tempo. ${ }^{17}$ Quando questionados sobre o ranking de dificuldades para incorporar hábitos alimentares saudáveis no dia a dia, respondiam:

Sarah: [...] primeiramente o mais difícil (dificuldade) é tempo, pelo menos assim, pela minha parte normalmente eu saio de casa de manhã e só volto à noite de 10 horas da noite, depois da aula né? então assim, a maioria das minhas refeições eu faço fora [...].

A falta de tempo também revela outro fator para a não busca por alimentos saudáveis: a praticidade dos alimentos industrializados. Hoje, nos supermercados da maioria das cidades brasileiras, é possível adquirir alimentos resfriados, congelados, temperados, preparados, empanados, recheados, etc. ${ }^{6}$ São mais rápidos, vendidos prontos ou semiprontos e têm uma boa durabilidade - por isso, a procura por esses produtos é grande, principalmente pelos que passam o dia fora de casa: "[...] a facilidade de adquirir e armazenar. Porque compra, tá ali e qualquer hora que você quer, já tá pronto pra consumir!" (Thales).

O consumo médio de frutas e hortaliças ainda é metade do valor recomendado pelo Guia Alimentar para a População Brasileira e manteve-se estável na ultima década, enquanto alimentos ultraprocessados, como doces e refrigerantes, têm seu consumo aumentado a cada ano. ${ }^{16} \mathrm{Já}$ as frutas são cada vez menos incorporadas, por serem mais perecíveis para o consumo diário das pessoas que realizam a maioria das refeições fora de casa. Este é um dos motivos alegados para o baixo consumo frutas no dia a dia:

Marilena: [...] Tenho duas limitações, duas dificuldades muito grandes! Uma [...] é sair de 5 h da manhã de casa, e às vezes chego de $20 \mathrm{~h}$ da noite. [...] eu não sei manusear, já tentei transportar. Banana, maçãa, quando chega no trabalho lá, tá preta a casca da banana. 
Apesar disso, pode-se inferir que as frutas também são alimentos prontos, podem ser consumidas frescas ou secas (desidratadas), como parte das refeições principais ou como lanches, nos intervalos entre essas refeições. ${ }^{17} \mathrm{Um}$ aspecto diferenciado sobre elas, que vale a pena ser ressaltado, é que não exigem técnicas demoradas de preparo para o consumo, como é reconhecido abaixo:

Heloísa: Eu acho prático, você não tem que cozinhar pra comer uma fruta, você vai lá e no máximo o que você faz, você descasca, no máximo! Então é fácil, é uma coisa saudável [...]

\section{Práticas alimentares arraigadas}

Segundo o Glossário Temático Alimentação e Nutrição, práticas alimentares são usos, hábitos e costumes que definem padrões de consumo alimentar de acordo com os conhecimentos científicos e técnicos de uma boa alimentação. ${ }^{18}$ Esse processo deve ser incentivado desde a infância:

Louise: Foi uma questão assim, de educação mesmo. Eu não fui educada a comer frutas, e eu não tenho esse hábito de comer frutas. [...]

A educação alimentar e nutricional oferece auxílio substancial para repensarmos os porquês deste cenário e como podemos nos portar diante dele. O lançamento do Marco de Referência de Educação Alimentar e Nutricional para as Políticas Públicas veio fortalecer o avanço desse conceito:

Portanto, 'Educação Alimentar e Nutricional', no contexto da realização do Direito Humano à Alimentação Adequada e da garantia da Segurança Alimentar e Nutricional, é um campo de conhecimento e de prática contínua e permanente, transdisciplinar, intersetorial e multiprofissional que visa promover a prática autônoma e voluntária de hábitos alimentares saudáveis. A prática da EAN deve fazer uso de abordagens e recursos educacionais problematizadores e ativos que forneçam o diálogo junto aos indivíduos e grupos populacionais, considerando todas as fases do curso da vida, etapas do sistema alimentar e as interações e significados que compõem o comportamento alimentar. ${ }^{1}$

Destacamos que a educação nutricional à qual nos referimos diz respeito a um processo de aprendizagem, e não de adestramento ${ }^{10}$. A educação alimentar e nutricional não preconiza uma obediência passiva a dietas. Ela proporciona acesso a informações, mas trabalha também os aspectos subjetivos da alimentação, para que mudanças possam acontecer no tempo e no ritmo de cada pessoa. Ela deve estar sintonizada com uma constante reflexão sobre o sistema alimentar onde o indivíduo se insere. Por isso, a educação alimentar e nutricional não é uma tarefa banal. ${ }^{1}$

O papel da educação alimentar e nutricional está vinculado à produção de informações que sirvam como subsídios para auxiliar a tomada de decisões dos indivíduos que outrora foram culpabilizados por sua ignorância. Estes são posteriormente vítimas da organização social capitalista e se tornam providos de direitos e são convocados a ampliar seu poder de escolha e decisão. ${ }^{19}$ Para a formação de práticas alimentares saudáveis, a falta de informação também foi citada: 
Simone: [...] Eh... acho que a falta de informação, porque com a informação você pelo menos, tenta outras alternativas. Se você não tem a informação, você vai continuar naquela.

A educação em saúde é um conjunto de práticas que contribui para aumentar a autonomia das pessoas no seu cuidado e no debate com profissionais da saúde e gestores. Aliada à promoção de modos de vida saudáveis, a promoção de práticas alimentares saudáveis é uma estratégia de vital importância para o enfrentamento dos problemas alimentares e nutricionais do contextoatual. ${ }^{1}$ Como nas orientações sobre o a importância do consumo de água realizadas no projeto de extensão pelo pesquisador, que fizeram efeito e mostraram que realmente a mudança da prática alimentar é gradativa, mas necessita de uma sensibilização eficiente e diária diante dos porquês das mudanças e estratégias escolhidas:

Marilena: Eu me policio agora. Depois, faz uns... depois dessas histórias das orientações de água, eu bebo bem mais água! E hoje, hoje eu tô mais... eu tô uma mocinha quase. (risos).

Seres humanos são seres sociais, e o hábito de comer em companhia está impregnado em nossa história, assim como a divisão da responsabilidade por encontrar ou adquirir, preparar e cozinhar alimentos. Compartilhar o comer e as atividades envolvidas com este ato é um modo simples e profundo de criar e desenvolver relações entre pessoas. Desta forma, comer é uma parte natural da vida social. ${ }^{17} \mathrm{O}$ ato de comer também é um fato social, por isso os momentos de comensalidade podem influenciar nosso comportamento diante das escolhas alimentares, como é refletido no trecho abaixo:

Elizabeth: E o outro [aspecto] é realmente a cultura, o ambiente que a gente vive, [...] É meio que, se você for conduzida pra uma alimentação mais saudável, é meio que você vai sendo excluída. Existe uma questão muito cultural no meio, se você... se você começar a ter algumas práticas e excluindo algumas coisas, as pessoas vão lhe excluindo. [...]

\section{Falta de acesso a modos de vida saudáveis}

Uma dificuldade também evidenciada foi com relação ao acesso, no que diz respeito às dimensões física e financeira. Alimentos in natura ou minimamente processados - antes comumente comercializados em mercearias, quitandas, açougues e pequenos mercados localizados próximos às casas das pessoas - hoje tendem a ser adquiridos em supermercados distantes das moradias. A distância faz com que as compras de alimentos sejam semanais ou mesmo mensais, o que diminui a disponibilidade nas casas de alimentos perecíveis, como frutas, verduras e legumes. ${ }^{17}$ Essa tendência para a compra de alimentos é vivenciada abaixo:

Sarah: [...] Aonde comprar? Por aqui como eu passo o dia fora, é muito raro assim ter um canto saudável. Eu vou ali fora, é um 'bucado' de barraquinha, eu como um salgado, ou alguma coisa durante a tarde, durante a manhã, um Todinho. [...] 
Jamie Oliver coloca que as empresas precisam assumir a responsabilidade de alimentar seus trabalhadores de forma apropriada, considerando o que eles tornam acessível para seus trabalhadores se alimentarem. ${ }^{20} \mathrm{O}$ acesso no ambiente de trabalho ou estudo foi um dos principais fatores citados como dificuldade para a falta ou redução do consumo adequado de água no dia a dia. Eles alegam que os locais com água disponível para beber estão distantes de seu setor de trabalho, implicando novamente a falta de tempo, uma realidade constatada abaixo:

Susanne: Aqui, é a distância mesmo. Que eu tenho que descer 4 lances de escada, pra ir pro bebedouro tomar água. [...]

Nos dados das Pesquisas de Orçamentos Familiares (POF) da década de 1990, nota-se que a participação de carboidratos nas dietas tende a declinar entre as pesquisas nas áreas metropolitanas do Norte-Nordeste, sendo esse declínio compensado, em partes semelhantes, pelo aumento na oferta de proteínas e de lipídios. A fração do açúcar refinado (sacarose) cresce sobre a fração dos demais carboidratos, tanto no Norte-Nordeste quanto no Centro-Sul. Nas duas regiões, a proporção das calorias totais provenientes de carboidratos complexos, os quais representam a imensa maioria dos "demais carboidratos", fica bastante aquém do limite mínimo recomendado de 50\%. ${ }^{21}$ Então, alimentos ricos em açúcares e gorduras tendem a oferecer maior custo benefício aos consumidores em relação ao aporte energético, ou seja, mais energia com menos custo. Isso faz com que se compre menos frutas, pois por serem menos calóricas, precisam ser compradas em maior quantidade e resultam em custo maior:

Hannah: [...] Eu citaria o dinheiro. Porque depois que eu comecei a fazer a feira, eu sei o quanto é caro, você ficar comprando fruta. (risos)

\section{O saudável não é saboroso}

Uma vez que a alimentação se dá em função do consumo de alimentos e não de nutrientes, uma alimentação saudável deve ser baseada em práticas alimentares que tenham significado social e cultural. Os alimentos têm gosto, cor, forma, aroma e textura, e todos esses componentes precisam ser considerados na abordagem nutricional. $\mathrm{O}$ argumento da ausência de sabor da alimentação saudável é outro tabu a ser desmistificado, pois uma alimentação saudável é e precisa ser pragmaticamente saborosa. O resgate do sabor como um atributo fundamental é um investimento necessário à promoção da alimentação saudável..$^{16}$ É o que pode ser evidenciado no trecho abaixo, sobre o consumo reduzido de frutas:

Elizabeth: Sabor. Não atrai muito. Atrai fisicamente né, é bonito num sei o que, você sabe que alié saudável, mas sabor... não traz tanto sabor quanto outros alimentos "traz". Pra mim, minha maior dificuldade é essa. [...] É porque o sabor não atrai muito. Se atraísse, lembrava. (risos) [...] não é o que me atrai de primeiro, então eu vou comer outras coisas. E fruta, não é preferência. 
Nesta medida, contrastam com os produtos prontos para consumo, cada vez mais "irresistíveis" em função dos avanços tecnológicos que oferecem à indústria possibilidades praticamente infinitas de manipulação do gosto, aroma, textura e aparência dos produtos. Produtos prontos para consumo são convenientes e atraentes. Dispensam ou diminuem substancialmente as atividades culinárias de preparação, tempero e cozimento, têm longa duração, podem ser estocados por grandes períodos e agradam muito ao paladar da maioria das pessoas. ${ }^{17}$ Portanto, ao contrário das frutas, a presença de sabor é mais citada para os alimentos industrializados, como os embutidos:

Susanne: Eu acho que é gostoooso mesmo! (risos) É gostoso, uma coisa com tempero ali no churrasco. Quem não come pelo amor de Deus? [...] todo mundo aqui tem noção de como é feito isso aí, eu tenho plena noção de como isso é feito e fabricado, mas assim não é que eu coma todo dia. [...] Mas que é gostoso é. Se eu pudesse, se fosse saudável igual a fruta, comia todo dia. (risos).

A sociedade contemporânea tem como característica a busca pelo prazer. Ter prazer se revela em viver uma vida melhor, em não se privar de nada, ou seja, é satisfazer suas necessidades emocionais, sejam elas corporais, sensoriais, estéticas, relacionais, lúdicas, entre outras. Para isso, o ser humano não se priva do supérfluo e o consumo passa a ser regido pelos sentimentos, principalmente pelo sentimento da felicidade. ${ }^{22}$ Essa busca pelo prazer traz uma relação muito forte do doce com essa sensação:

Louise: Porque doce é uma fonte de liberação de serotonina né?! É uma fonte de prazer e felicidade, digamos assim, instantânea.

Hannah: Eu acho que a dificuldade de tirar o doce, é que a sensação assim de prazer que o doce traz. [...]

Em geral, o método tradicional de educação nutricional se concentra nos efeitos biológicos dos nutrientes no organismo, na orientação alimentar, e ainda na preservação das propriedades nutritivas dos alimentos envolvendo técnicas de preparo e armazenamento. ${ }^{10}$ Jamie Oliver cita que, para recomeçar e realizar uma mudança tangível aos olhos, os supermercados devem, além de nos ajudar a comprar alimentos, ensinar as pessoas que estão ocupadas a cozinhá-los de forma rápida, saborosa e sazonal. ${ }^{20}$ Essa dificuldade é relatada abaixo:

Catarina: [...] é assim, pouco conhecimento sobre receitas gostosas e saudáveis. (risos) Porque eu acho que a gente discute pouco isso. Ai talvez se a gente começasse a conversar mais, "ah, como é que faz um prato assim? Ah, deve ficar tão gostoso". Porque a gente sabe fazer lasanha, escondidinho, empadão...

Os brasileiros de todas as idades, incluindo crianças, adolescentes e adultos, passam em média mais de cinco horas por dia diante de aparelhos de televisão. Durante uma parte considerável deste tempo, são expostos a publicidades comerciais, sendo substancial a fração correspondente à propaganda de alimentos, em particular de produtos prontos para consumo e ultraprocessados. ${ }^{17}$ Segundo Lipovetsky, os atores do marketing louvam os méritos dos produtos que possibilitam ao consumidor viver experiências imaginárias, afetivas e sensoriais ${ }^{23}$ sendo o consumo emocional, a 
relação entre a marca e as boas lembranças: reuniões de família e amigos, eventos comemorativos ou histórias do passado. Por isso, a utilização de valores e ideias precisam ser inseridas na marca. ${ }^{22}$

Um dos princípios da educação trazidos à tona é a força daquilo que aprendemos quando pensamos que não estamos aprendendo. ${ }^{1}$ A propaganda como veiculadora de ideias ligadas a alimentação e nutrição talvez atue nesta brecha, objetivando ensinar práticas alimentares, para que estas sejam aprendidas e incorporadas ao dia a dia de forma discreta. Essa situação é percebida abaixo:

Tales: Ah, não tenho muita dificuldade. Acho que assim, que as pessoas compram mais esses produtos industrializados, primeiro acho que é o marketing. [...] Mas a Coca®e o Guaraná@ fizeram uma propaganda que até hoje é influência pesada pra mim, porque pipoca pra mim tem que ser com guaraná! (risos e gargalhadas) [...] eu acho que foi uma propaganda tão pesada... [...] até a música eu sei! Assim, eu não gosto do Guaraná, se for tomar uma latinha de Guaraná eu não tomo ela toda [...] Mas se for com pipoca, é botando Guaraná e pipoca [...] (risos). Ai a Coca, é a mesma coisa da pizza, porque o refrigerante que eu gosto mais é o laranja, mas assim se for com a pizza ou com peixe frito, ai tem que ser a Coca Cola. [...].

\section{"A dieta é sacrifício"}

Hoje, a dieta é vista pelas pessoas como um regime alimentar no qual elas precisam restringir alguns alimentos por motivo de doenças, só que o significado de dieta vai muito mais além disso. Uma dieta saudável precisa ser vista como algo do cotidiano, sendo uma forma de as pessoas cuidarem de si mesmas. Foucault refere-se ao cuidado de si mesmo como o fato de ocupar-se consigo, de preocupar-se consigo. ${ }^{24}$ Sendo assim, se a dieta saudável implica um cuidado diário, as pessoas não devem se sentir fora desse processo, mas sujeitos ativos nas próprias escolhas alimentares.

Os hábitos e estilo de vida estão intimamente associados à condição de saúde das pessoas. Integram, assim, o amplo espectro de questões - sociais, econômicas, políticas e culturais - que envolvem a promoção da saúde, que constitui condição essencial à qualidade de vida individual e coletiva. ${ }^{25}$ Atualmente, percebe-se que tais fatores contribuem para uma alteração no panorama epidemiológico mundial, no qual as doenças crônicas não transmissíveis tais como a obesidade, o diabetes tipo II, as alterações cardiovasculares, assim como alguns tipos de câncer, assumiram destaque, visto que suas prevalências vêm aumentando consideravelmente. A maioria destas doenças apresenta etiologia relacionada com aspectos comportamentais, como a alimentação e o exercício físico, os quais também têm sido historicamente alterados, desde o homem primitivo. ${ }^{26}$ A preocupação com as doenças crônicas não transmissíveis já é evidente no campo da saúde pública, mas quando o processo de adoecer é algo de longo prazo, isso traz uma comodidade na vida das pessoas, e as mudanças na alimentação continuam sendo deixadas de lado, como relatado a seguir: 
Elizabeth: [...] pelo menos no meu caso, na minha genética, não sei... eu não sinto os efeitos tão rápido. Digamos assim, sei lá... diabetes, obesidade, colesterol elevado. Comigo não, graças a Deus os efeitos ruins não são tão rápidos, e aí eu não ligo, digamos assim entendeu? Como eu não vejo, não é uma coisa que cause logo um efeito, você... "ah, amanhã eu como melhor", digamos assim. Vai passando...

A crescente substituição dos alimentos in natura ricos em fibras, vitaminas e minerais, por produtos industrializados, compõe um dos principais fatores etiológicos da obesidade. ${ }^{6}$ Os doces em geral são reconhecidos como aqueles que precisam ser consumidos com moderação, devido a sua associação com doenças como diabetes e obesidade:

Louise: Doce é uma angústia pra mim, porque... eu tenho resistência a insulina. Então, eu não... posso comer doce, mas eu não resisto! Assim, eu não como todos os doces. Eu não como bolo, não como torta, eu não como... eu só como chocolate! [...]

Marilena: [...] Eu já arranquei o pedaço da unha aqui, do corinho, pensando nisso aí. [...] antes da cirurgia, já não podia comer né, porque eu comia e dava aquela dor! Aí fui retirar a vesícula [...] isso mexeu com todo meu psicológico. Tirar doce de uma vez! [...] tudo que eu comia, chocolate já era, até hoje ainda... não me adaptei. [...] Meu docinho de leite, já era. [...] eu fiquei me sentindo assim "a diabética”. [...] Então qual a minha dificuldade? Porque eu tenho vontade, e não posso comer [...].

A dieta vista como sacrifício é percebida pelos sujeitos como uma prática exterior às suas vidas, algo que será realizado para evitar um mal, e não como uma prática produtora de vida, cotidiana e prazerosa. A saúde deve ser vista como um recurso para a vida e não como objetivo de viver. ${ }^{16}$ A liberdade e a restrição, como nunca visto antes, travam a luta do equilíbrio no controle individual dos corpos. Carecemos de normas. Quanto mais inseguros, mais vemos florescer a multiplicidade de discursos oferecidos pelo mercado para nos "ajudar" a lidar com nossos medos dietéticos. O discurso da ciência da Nutrição é mais um dos milhares com que se depara o comensal contemporâneo com sua busca pelo "comer bem". Devido ao sem-fim de fatores que transpassam a alimentação, talvez não consigamos chegar a uma teoria alimentar que sintetize o bem comer. ${ }^{27}$

\section{Estratégias}

\section{EAN como prática cotidiana}

A nova instantaneidade do tempo muda radicalmente a modalidade do convívio humano - e mais conspicuamente o modo como os humanos cuidam (ou não cuidam, se for o caso) de seus afazeres coletivos; ou antes, o modo como transformam (ou não transformam, se for o caso) certas questões em questões coletivas. ${ }^{28}$

O elenco de estratégias na saúde direcionadas à Promoção da Alimentação Adequada e Saudável (PAAS) envolve a educação alimentar e nutricional, que se soma às estratégias de regulação dos 
alimentos - envolvendo rotulagem e informação, publicidade e melhoria do perfil nutricional dos alimentos - e ao incentivo à criação de ambientes institucionais promotores de alimentação adequada e saudável, incidindo sobre a oferta de alimentos saudáveis nas escolas e nos ambientes de trabalho. O desenvolvimento de habilidades pessoais em alimentação e nutrição implica pensar a educação alimentar e nutricional como processo de diálogo entre os profissionais de saúde e a população, de fundamental importância para o exercício da autonomia e do autocuidado. ${ }^{29} \mathrm{~A}$ orientação nutricional nos setores, durante o projeto de extensão desempenhado pelo pesquisador, foi uma das estratégias que funcionou, e poderia ser usada nos ambientes de trabalho, como é descrito a seguir:

Edith: Quando Mariana começou a dar... ah... passar essas informações pra gente nos setores, ela levou um sobre a água: "Você já tomou água hoje?". E aí ficava lá no quadro de avisos. Toda vez que eu passava que eu via, "você já tomou água hoje?", aí ia direto tomar água [...] (risos).

Maria: [...] foi uma estratégia que eu comecei a usar. E eu acho que poderia servir, com relação a água. Colocar uma garrafinha, trazer de manhã uma garrafinha, fica muito mais fácil quando a água tá ali perto da gente. Pelo que eu percebi, a maioria das pessoas daqui não consomem tanta água pela dificuldade do acesso. [...] Então eu acho que se a gente trouxesse uma garrafinha e deixasse na mesa, não tem como não tomar [...].

O vídeo passado no segundo momento com os grupos focais também foi reconhecido como uma boa ferramenta de educação alimentar e nutricional, para sensibilizar sobre os riscos do elevado consumo de alimentos industrializados:

Tales: É, o vídeo eu acho muito interessante! [...] eu pelo menos acho que diminuiria meus biscoitos recheados. (risos)

\section{EAN como política alimentar}

A realização de qualquer direito humano pode e deve ser exigida dos Estados, de diversas maneiras e nas várias esferas do governo. Um dos aspectos fundamentais para que esta exigência ocorra é que os cidadãos, os agentes públicos e a sociedade civil estejam informados sobre seus direitos e obrigações. ${ }^{30}$

O direito humano à alimentação adequada é:

[...] um direito humano inerente a todas as pessoas de ter acesso regular, permanente e irrestrito, quer diretamente ou por meio de aquisições financeiras, a alimentos seguros e saudáveis, em quantidade de qualidade adequadas e suficientes, correspondentes às tradições culturais do seu povo e que garantam uma vida livre do medo, digna e plena nas dimensões física e mental, individual e coletiva. Portanto, se realiza "quando todo homem, mulher e criança, sozinho ou em comunidade com outros, tem acesso físico e econômico, ininterruptamente, a uma alimentação adequada ou aos meios necessários para sua obtenção". ${ }^{30}$ 
Sendo assim, a promoção e a plena realização do DHAA compreendem elementos amplos de justiça social e econômica de um país, como reforma agrária; política agrícola; valorização da agricultura familiar, de políticas de abastecimento, de incentivo a práticas agroecológicas; não discriminação de povos, etnia e gênero; vigilância sanitária dos alimentos; abastecimento de água e saneamento básico; alimentação escolar; atendimento pré-natal de qualidade; promoção do aleitamento materno, entre outros. ${ }^{30}$ É por isso que a possibilidade de saúde não se produz a partir do momento em que o indivíduo faz a escolha sobre o que comer. Começa desde quando uma nação decide o que planta, o quanto investe nisso, como subsidia o acesso a alimentos para a população, entre outros - ou seja, fazer educação nutricional também envolve fazer e discutir política.

O debate em torno na promoção da saúde parte do pressuposto de que saúde e qualidade de vida não dependem do oferecimento isolado de um dado serviço, mas da oferta de um conjunto de condições de vida e de trabalho. ${ }^{10}$ Muitas vezes, orientar sobre práticas alimentares saudáveis não é suficiente para garantir que elas sejam incorporadas, pois as condições ambientais nem sempre são favoráveis. Por isso, quanto ao acesso para a ingestão diária de água, foi sugerido: "Mais bebedouros espalhados pelo hospital" (Simone).

Ambientes que não favorecem padrões saudáveis de alimentação, de modo algum incomuns, implicam a necessidade de que a educação sobre alimentação não se restrinja a informar as pessoas sobre os atributos daqueles padrões. Igualmente importante é capacitar as pessoas - neste caso como cidadãos - a identificar os obstáculos que dificultam a prática de uma alimentação saudável, as ações capazes de remover esses obstáculos e os caminhos e estratégias para concretizar essas ações. ${ }^{16}$ Então, se o local de trabalho não dá condições para uma alimentação mais saudável, podese criar estratégias que envolvam o grupo, por exemplo:

Marilena: A gente não costuma fazer lanche aqui no setor? Pronto, vamos comprar fruta, deixar estocado fruta!

O fortalecimento ou ampliação dos graus de autonomia para as escolhas e práticas alimentares implica, por um lado, aumento da capacidade de interpretação e análise do sujeito sobre si e sobre o mundo e, por outro, a capacidade de fazer escolhas, governar e produzir a própria vida. ${ }^{29}$ As pessoas podem formular estratégias pessoais para driblar suas próprias dificuldades:

Maria: Eh, uma coisa que eu fiz pra conseguir resistir ao doce, foi não comprar, eu não compro doce, eu não tenho em casa nada de doce, eu deixo pra comer doce quando eu vou pra uma festa, e aí eu não abro mão, eu como em pequena quantidade também, porque antes eu comia muito realmente, mas eu reduzi a quantidade [...].

A mobilização da sociedade, dos profissionais e dos gestores em torno da promoção da alimentação adequada e saudável só será possível quando este tema - enquanto expressão de cidadania e fator protetor da vida - for valorizado. Para que isto ocorra, é preciso reconhecer a complexidade do tema; as diferentes visões existentes no interior da sociedade; um profundo 
conhecimento das diferentes práticas alimentares da população brasileira e seus determinantes; o entendimento de que o impacto almejado necessita de ações permanentes e que os resultados são de médio e longo prazos. ${ }^{1}$

Verduras, legumes e frutas estão usualmente entre os itens mais caros de uma alimentação baseada em alimentos e ingredientes culinários. Comprar hortaliças e frutas em feiras de produtores e outros locais, como "sacolões" ou "varejões", onde há menos intermediários entre o agricultor e o consumidor final, também pode reduzir custos. ${ }^{17} \mathrm{Hoje}$ em dia, não só os supermercados, mas também os mercados menores próximos às nossas casas, reservam um dia de promoção para esses alimentos (frutas, legumes e verduras), normalmente no dia em que a mercadoria chega, ou seja, além do baixo custo, os alimentos estão mais frescos:

Edith: Lá perto da minha casa tem assim uma feirinha, pronto hoje é quinta feira dia da verdura e fruta, então verdura e fruta na quinta feira é mais barato [...].

Portanto, considerando que o meio nem sempre favorece o acesso a formas de vida saudáveis, caberia ao Ministério da Saúde criar medidas que ajudassem as pessoas, como: fomentar a agricultura familiar, favorecendo a implantação feiras-livres, e estimulando por meio de subsídios financeiros, alimentos que tendem a ser mais caros devido à redução de seu tempo de prateleira, como por exemplo, o arroz integral, aumentando o valor nutritivo da dieta com o custo mais acessível.

\section{EAN nas escolas}

No PNAE (Política Nacional de Alimentação nas Escolas), por exemplo, o progressivo fortalecimento da EAN culminou na Lei no $11.947,{ }^{31}$ onde uma diretriz prevê:

[...] a inclusão da educação alimentar e nutricional no processo de ensino e aprendizagem, que perpassa pelo currículo escolar, abordando o tema alimentação e nutrição e o desenvolvimento de práticas saudáveis de vida, na perspectiva da segurança alimentar e nutricional. ${ }^{1}$

Essa necessidade é reconhecida abaixo:

Marilena: Era pra ser matéria obrigatória [...] a orientação nutricional desde criança.

Jamie Oliver, ressalta a importância de ensinar às crianças nas escolas sobre alimentação e nutrição, pois essas habilidades culinárias devem ser valores cultivados desde cedo. É importante que as crianças saiam da escola sabendo cozinhar pelos menos dez receitas que salvarão suas vidas. Isso significa que não importa quem eles sejam - estudantes, jovens ou adultos -, serão capazes de aplicar as bases da cozinha, não importa em qual tempo em eles vivam, se souberem cozinhar, o tempo não importa. ${ }^{20}$

Não só ensinar como cozinhar os alimentos, mas também trabalhar a publicidade que gira em torno do tema da alimentação. É crescente a quantidade de matérias em programas de televisão, rádio, revistas e internet com informações e recomendações relacionadas a alimentação e saúde. 
Com frequência, essas matérias enfatizam alimentos específicos, propagados como "superalimentos" e ignoram a importância de variar e combinar alimentos. ${ }^{17}$ Alimentos nutricionalmente ricos devem ser valorizados e entrarão naturalmente na dieta adotada, sem que se precise mistificar uma ou mais de suas características. ${ }^{16}$

Estimular também os bons hábitos alimentares desde os momentos de alimentação na escola, estes valores, quando aprendidos de fato, são levados para casa pelas crianças e cultivados em família. Refeições regulares consumidas com atenção e sem pressa favorecem a digestão dos alimentos e também evitam que se coma mais do que o necessário. As características do ambiente onde comemos influenciam a quantidade de alimentos que ingerimos e o prazer que podemos desfrutar da alimentação. Cheiros, sons, iluminação, conforto, condições de limpeza e outras características do lugar são importantes. ${ }^{17}$

Uma alternativa de ação para a alimentação saudável deve favorecer, por exemplo, o deslocamento do consumo de alimentos pouco saudáveis para alimentos mais saudáveis, respeitando a identidade cultural-alimentar das populações e comunidades. As proibições ou limitações impostas devem ser evitadas, a não ser que façam parte das orientações individualizadas e particularizadas do aconselhamento nutricional de pessoas portadores de doenças ou distúrbios nutricionais específicos, devidamente fundamentadas e esclarecidas. ${ }^{16}$

\section{CONCLUSÃO}

Foi possível perceber, pelo diagnóstico nutricional simplificado, que o perfil antropométrico dos funcionários é de $43 \%$ com sobrepeso ou obesidade. Dentre outros fatores, isso pode ser devido aos maus hábitos alimentares.

Quanto às dificuldades encontradas para incorporar hábitos alimentares saudáveis, o diálogo estabelecido permitiu o fechamento das seguintes categorias: não há tempo, pois a instantaneidade da vida moderna tem gerado falta de tempo para coisas que são fundamentais, como se alimentar, modificando assi o convívio humano e suas necessidades; as práticas alimentares arraigadas, quando não saudáveis, carecem de mudança gradativa, e é quando a educação alimentar e nutricional entra em cena para propor a alimentação como prioridade, possibilitando o acesso à informações que darão ao indivíduo autonomia para realizar suas escolhas; a falta de acesso a modos de vida saudáveis, relacionada com a disponibilidade para compra de alimentos que muitas vezes encontrase dificultada, pelo acesso físico aos locais de venda e o custo dos alimentos saudáveis; o saudável não é saboroso, principalmente porque o sabor está muito ligado à formação de gosto - portanto, estimular as habilidades culinárias é fundamental para que o alimento se torne mais atraente; por fim, a dieta é sacrifício, pois as pessoas ainda não a reconhecem como promotora de saúde, mas como um sacrifício para evitar um mal. 
Com base no exposto, a educação nutricional deve ser vivida na prática cotidiana a partir do momento em que as orientações nutricionais são focadas no autocuidado, dando às pessoas a autonomia de escolha para promoção da própria saúde. A alimentação adequada e saudável precisa ser reconhecida enquanto expressão da cidadania e fator protetor à vida. E já que a cidadania é aprendida desde a infância nas escolas, a EAN também deve ser vista e incentivada nesses ambientes como processo de ensino e aprendizagem, estimulando desde as habilidades culinárias até as boas práticas alimentares.

O que se pode aplicar nas escolas também se estende aos ambientes de trabalho, onde as empresas devem assumir o papel de responsáveis pela saúde de seus funcionários, estimulando práticas alimentares adequadas e saudáveis, dentre outras medidas.

Diante dos poucos estudos que tratam essa temática dessa forma, são necessários mais estudos como esse em outros ambientes de trabalho, que também não estejam relacionados à saúde, a fim de averiguar o que profissionais de outras áreas pensam sobre alimentação e quais as dificuldades enfrentadas por eles nesses ambientes.

\section{AGRADECIMENTOS}

Nossos agradecimentos aos funcionários do Hospital de Pediatria da Universidade Federal do Rio Grande do Norte, que foram fundamentais para a concretização deste trabalho.

\section{REFERÊNCIAS}

1. Brasil. Ministério do Desenvolvimento Social e Combate à Fome. Secretaria Nacional de Segurança Alimentar e Nutricional. Marco de referência de educação alimentar e nutricional para as políticas públicas. Brasília: MDS; 2012. 36 p.

2. Boog MCF. Pesquisar para compreender, compreender para interagir. In: Boog MCF. Educação em nutrição: integrando experiências. Campinas: Komedi; 2013. p. 115-130.

3. Duncan BB, Chor D, Aquino EML, Bensenor IM, Mill JG, Schmidt MI, et al. Doenças crônicas não transmissíveis no Brasil: prioridade para enfrentamento e investigação. Rev. Saúde Pública 2012; 46(Supl):126-34.

4. Pinheiro ARO, Freitas SFT, Corso ACT. Uma abordagem epidemiológica da obesidade. Rev. Nutr. 2004; 17(4):523-33.

5. Bastista Filho M, Rissin A. A transição nutricional no Brasil: tendências regionais e temporais. Cad. Saúde Pública 2003; 19(Sup. 1):181-91.

6. Tardido AP, Falcão MC. O impacto da modernização na transição nutricional e obesidade. Rev. Bras. Nutr. Clin. 2006; 21(2):117-24. 
7. Azevedo ACS, França MG, Heck AM, Mozzatto MCR, Polita RO, Silva RC. Perfil nutricional dos funcionários do Hospital São Vicente de Paulo. Rev. Médica HSVP 2003; 15(32):34-37.

8. D’Alencar ER, Lima MMR, Mendonça PML, Custódio IL, D’Alencar BP, Lima FET. Ações de educação em saúde no controle do sobrepeso/obesidade no ambiente de trabalho. Rev. Rene [Internet] 2010; 11(1). Disponível em: http://www.revistarene.ufc.br/vol11n1_html_site/a18v11n1.htm

9. Coutinho JG, Gentil PC, Toral NA. Desnutrição e obesidade no Brasil: o enfretamento com base na agenda única da nutrição. Cad. Saúde Pública 2008; 24(Supl):332-40.

10. Ferreira VA, Magalhães R. Nutrição e promoção da saúde: perspectivas atuais. Cad. Saúde Pública 2007; 23(7):1674-81.

11. Bauer MW, Gaskell G. Pesquisa qualitativa com texto, imagem e som. Um manual prático. $6^{a}$ ed. Petrópolis, RJ: Vozes; 2007.

12. Universidade Federal do Rio Grande do Norte. Departamento de Nutrição. Manual de capacitação para procedimentos antropométricos. Natal: UFRN; 2006/2007.

13. Portal da Saúde. Programa Nacional de Alimentação e Nutrição. Como está sua alimentação? [Internet]. [acesso em: 12 maio 2013]. Disponível em: http://nutricao.saude.gov.br/teste_alimentacao.php

14. Nóbrega SM, Coutinho MPL. O teste de associação livre de palavras. In: Coutinho MPL, Lima AS, Oliveira FB, Fortunato ML, organizadores. Representações sociais: abordagem interdisciplinar. João Pessoa: Editora Universitária; 2003. p. 67-77.

15. Bardin L. Análise de conteúdo. Lisboa: Persona; 1977.

16. Brasil. Ministério da Saúde. Secretaria de Atenção à Saúde. Coordenação Geral de Política de Alimentação e Nutrição. Guia alimentar para a população brasileira: promovendo a alimentação saudável. Brasília: Ministério da Saúde; 2005. 217 p.

17. Brasil. Ministério da Saúde. Secretaria de Atenção à Saúde. Coordenação Geral de Política de Alimentação e Nutrição. Guia alimentar para a população brasileira. 2a ed. Brasília: Ministério da Saúde; 2014. 152 p.

18. Brasil. Ministério da Saúde. Secretaria Executiva. Secretaria de Atenção Básica a Saúde. Glossário temático alimentação e nutrição. Brasília: Editora Ministério da Saúde; 2008. 60 p.

19. Santos LAS. Educação alimentar e nutricional no contexto da promoção de práticas alimentares saudáveis. Rev. Nutr. 2005; 18(5):681-92.

20. TEDTalks. Jamie Oliver: ensinar alimentação a todas as crianças [Vídeo]. Produção de TEDTalks, 2012. 1 vídeo: 22 min., sonoro, color. [acesso 17 maio 2014]. Disponível em: https://www.youtube. $\mathrm{com} /$ watch? $\mathrm{v}=\mathrm{zA} 83 \mathrm{ASH}$ riAM

21. Monteiro CA, Mondini L, Costa RBL. Mudanças na composição e adequação nutricional da dieta alimentar nas áreas metropolitanas do Brasil (1988 - 1996). Rev. Saúde Pública 2000; 34(3):251-58.

22. Xavier LHS. Juventude e consumo emocional nas redes sociais da internet. Análise das marcas: Coca-cola, Pepsi, BlackBerry, Nokia, Riachuelo e C\&A [Dissertação]. [Natal]: Universidade Federal do Rio Grande do Norte; 2012. 
23. Lipovetsky GA. Felicidade paradoxal: ensaio sobre a sociedade de hiperconsumo. São Paulo: Companhia das letras; 2007. p. 402.

24. Santos MEE. Entre a hermenêutica do sujeito e filosofia mestiça: proposições para se pensar o esquecimento do cuidado de si e seus reflexos na educação. Fermentario 2013; 7(2):1-16.

25. Brasil. Ministério da Saúde. Secretaria Executiva. Subsecretaria de Planejamento e Orçamento. Plano Nacional de Saúde - PNS: 2012 - 2015. Brasília: Ministério da Saúde; 2011. 59 p.

26. Chaud DMA, Marchioni DML. Nutrição e mídia: uma combinação às vezes indigesta. Higiene Alimentar 2004; 18(116/117):18-22.

27. Medeiros M, Galeno A. Olhares sobre a alimentação contemporânea: a gastro-anomia e os corpos de Botero. Rev. Nutr. 2013; 26(4):465-472.

28. Bauman Z. Tempo/espaço. In: Bauman Z. Modernidade líquida. Rio de Janeiro: Jorge Zarah; 2001. p.127-149.

29. Brasil. Ministério da Saúde. Secretaria de Atenção à Saúde. Departamento de Atenção Básica. Política Nacional de Alimentação e Nutrição. Brasília: Ministério da Saúde; 2012. 88 p.

30. Leão MM, Recine EO. Direito humano à alimentação adequada. In: Taddei JÁ, Lang RMF, LongoSilva G, Toloni MHA. Nutrição em Saúde Pública. Rio de Janeiro: Rubio; 2011. p. 471-488.

31. Brasil. Lei no 11.947, de 16 de junho de 2009. Programa Nacional de Alimentação Escolar - PNAE. Diário Oficial da União 17 jun. 2009. [acesso em: 02 abr. 2013]. Disponível em: http://presrepublica. jusbrasil.com.br/legislacao/711767/lei-11947-09\#art-12 